\title{
The conditioned licking response in rats as a function of the CS-UCS interval
}

ROBERT BOICE AND M. RAY DENNY

MICHIGAN STATE UNIVERSITY

\begin{abstract}
Using a newly developed method of classical conditioning of the licking response in rats, the acquisition of test trial responses and anticipatory CRs was compared over five CS-UCS intervals ( $0.5 \mathrm{sec} ., 1 \mathrm{sec} ., 2$ sec., 4 sec., and 6 sec.). Results: (a) The optimal interval was $2 \mathrm{sec}$. with $4 \mathrm{sec}$. being nearly as good. (b) The 0.5, 1 and 6 sec. groups were not significantly different from one another. (c) Learning curves for CRs and test trials indicated the same trends with effects greater for the CRs.
\end{abstract}

\section{Introduction}

The notion that there is no single optimal CS-UCS interval in classical conditioning dates back to Pavlov (1927) who found a variety of temporal intervals up to $5 \mathrm{sec}$. to be equally efficacious. In the interim, American investigators have largely neglected using the consummatory response as a UCR and have focused on eyelid and finger withdrawal conditioning studies with humans, which have consistently indicated an optimal $1 / 2 \mathrm{sec}$. interval. In work with infra-human species the optimal CS-UCS interval has varied considerably. Goodstein et al, (1964) used frogs as the Ss, the nictitating membrane as the UCR, and found a 2 sec. CS-UCS interval to be most efficient.

The particular method used in this study was developed by Weisman (1965) as a technique to compare concurrent classical and instrumental conditioning of the same response. His data on successive acquisitions and extinctions, on partial reinforcement effects, and his controls for psuedo-conditioning and superstitious behavior combine to demonstrate evidence for a genuine classical conditioning procedure. Indications that the licking response in rats is highly reflexive (a good UCR) are present in the study by Keehn \& Arnold (1960). The question of innateness has been answered by Schaeffer \& Premack (1961) who observed weanling rats to lick in the same range as adults upon first contact with water. In view of past results where the UCR was a component of the consummatory response (salivation), it was expected that the optimal conditioning interval would probably be greater than $3 \mathrm{sec}$.

\section{Method}

The Ss were 40 naive female rats about four months of age, 20 grays and 20 albinos. The deprivation schedule was as follows: five days of $10 \mathrm{~min}$. of water per day; two days of $4 \mathrm{~min}$. of water per day; on training days, only $2 \mathrm{~min}$. of water outside the apparatus. All Ss were maintained in individual cages for the 12 day period with ad lib. food. Each animal was run at approximately the same time each evening.

The apparatus is described in detail elsewhere (Weisman, 1965). Essentially, two matched systems were used with the licker boxes enclosed in refrigerators. The licker boxes were modified to permit more confinement of the $\mathrm{S}$ than in Weisman's case (resultant dimensions $=5$ in long, 1-3/4 in wide, and 4 in high). The drinking well and front were constructed of plexiglass. An enclosed drinking well on the side of the box contained a No. 11 needle through which constant and small quantities of water were presented via a solenoid. A small copper ring encircled the opening to prevent gnawing and to measure licking. The CS was a 10 watt bulb next to the plastic drinking well.

The groups of albinos and grays were randomly divided into five groups of four each, making a total of five interval groups with eight Ss each. The five CS-UCS intervals chosen on the basis of pilot work were $0.5 \mathrm{sec}$., 1 sec., 2 sec., 4 sec., and 6 sec. All CS-UCS presentations were of the delayed type and had a 2 sec. overlap. After habituation (50 UCRs with no CS), each S was run in $3 \mathrm{hr}$. sessions for three days; the variable interval was 120 sec. Test trials were inserted on the average of one in 10 trials during the three 90-trial sessions.

Anticipatory responses and test trial responses were scored as CRs if they occurred during the time of the CS-UCS interval or CS duration, respectively, and were discriminatory in nature (not part of intertrial responding). To compensate for the obvious disadvantage of measuring anticipatory CRs with the two shortest intervals, test trials were used as the main measure of performance.

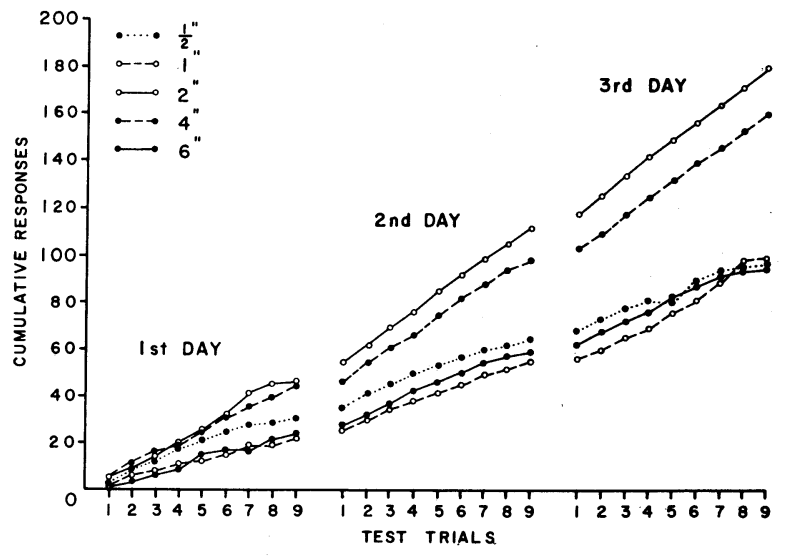

Fig. 1. Cumulative learning curves for test trial responses. 


\section{Results}

The data are graphically represented as cumulative acquisition curves (Fig. 1) and as parametric functions (Fig. 2). In Fig. 2 test trial responses are totaled for all three days whereas CR responses are shown only from the third day of acquisition. The 2 and 4 sec. groups showed a marked superiority in acquisition rates and in final levels of conditioning. Analysis of variance showed no significant difference between grays and albinos over all temporal intervals. For both responses, test trial and anticipatory, the intervals produced differences significant beyond the .005 level $(F=8.77$ and 30.85 respectively) Duncan's Multiple Range Test indicated the 2 and 4 sec. groups to condition significantly better than all other groups. The 2 sec. interval appears to be optimal, although it is not significantly so. The $0.5,1$, and 6 sec. interval groups are not significantly different from each other at any level in acquisition. Test trial functions for the three days maintain the same relationships between groups.

\section{Diseussion}

An interesting characteristic of the $0.5,1$, and $6 \mathrm{sec}$. groups was the inconsistency of UCR responding over trials, which resembled a sort of "inattention" on the part of the S. The 2 and $4 \mathrm{sec}$. groups, however, displayed almost perfect consistency in UCR responding over all $3 \mathrm{hr}$. sessions. Gormezano (1965) has mentioned some similar lapses in unconditioned salivary responding.

The effect of introducing some partial reinforcement during acquisition by omitting $1 / 10$ of the UCSs (test trials) was felt to be negligible in view of extensive pilot work where no differences were found. The fact that the 0.5 and 1 sec. intervals yielded a lower response level than their test trial counterparts (Fig. 2) was expected because in the latter case "conditioned responses" were counted during the $2 \mathrm{sec}$. CS overlap. That extra response time for test trial responses also produced a difference in the $6 \mathrm{sec}$.group which can not be attributed to simple response latency. In the later part of ac-

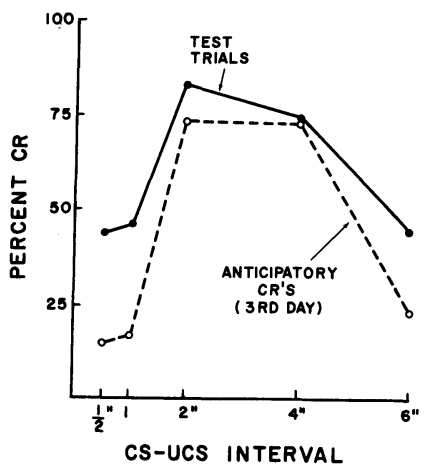

Fig. 2. Parametric functions for test trial responses and anticipatory responses (third day only).

quisition, the response tapes of the $6 \mathrm{sec}$.group showed marked evidence of inhibition of delay of the licking response in the CS-UCS interval. Here again the delayed response favored the test trial measure.

A group of rats exactly similar to those already described was run after the completion of the study proper to test a $16 \mathrm{sec}$. CS-UCS interval. The performance of this added group was essentially identical to that of the 6 sec. group.

\section{References}

Goldstein, A. C., Spies, G., \& Sepinwall, J. Conditioning of the nictitating membrane in the frog. J. comp. physiol. Psychol., 1964, 57, 456-458.

Gormezano, I. Classical conditioning. In J. B. Sidowski (Ed.), Experimental methods and instrumentation in psychology. New York: McGraw-Hill, 1965.

Keehn, J. D., \& Arnold, E. M. M. Licking rates in albino rats. Science, 1960, 132, 739-741.

Pavlov, I. P. Conditioned reflexes. (Translated by G. V. Anrep) London: Oxford University Press, 1957.

Schaeffer, R. W., \& Premack, D. Licking rates in infant albino rats. Science, 1961, 134, 1980-1981.

Weisman, R. G. A new method of classical conditioning in the rat: Comparisons with an instrumental conditioning technique using the same response. Amer. J. Psychol., 1965, in press. 